\title{
The use of molecular tools in invasion biology: an emphasis on freshwater ecosystems
}

\author{
S. BLANCHET \\ Station d'Ecologie Expérimentale du CNRS, U.S.R. 2936, 09200 Moulis, France and CNRS, UPS, ENFA; UMR5174 EDB \\ (Laboratoire Évolution et Diversité Biologique); 118 route de Narbonne, F-31062 Toulouse, France
}

\begin{abstract}
The potential uses of molecular tools to address issues in invasion biology are reviewed, including the early detection of novel and cryptic non-native species, the identification of introduction pathways and vectors, the understanding of the drivers in successful invasions and the assessment of effective population sizes during the establishment of new populations. The usefulness of molecular tools to assess the ecological and evolutionary consequences of biological invasions is discussed using recent examples in which the latest techniques in molecular ecology (e.g. high-throughput sequencing, DNA barcoding) are employed. This review highlights the versatility of molecular tools to provide information and insights on the ecological and evolutionary causes and consequences of biological invasions at different levels of biological organisation (i.e. gene, individual, population, community and ecosystem).
\end{abstract}

K EYW O R D S: DNA barcoding, exotic species, fish, high-throughput sequencing, microsatellites, molecular ecology.

\section{Introduction}

Biological invasions are one of the most serious human-induced threats to freshwater ecosystems (Copp et al. 2005; Dudgeon et al. 2006; Ricciardi 2007), but they also represent a unique opportunity for scientists to test theories related to species colonisation of, and adaptation to, new environments (Lodge 1993; Hochberg \& Gotelli 2005; Novak 2007; Sax et al. 2007). Therefore, the development of quantitative methods for understanding the ecological and evolutionary causes and consequences of biological invasions will have important fundamental and applied implications (Sax et al. 2007).

For instance, an understanding of the phenotypic and genetic characteristics of successful invaders (Jeschke \& Strayer 2006; García-Berthou 2007), as well as invasion pathways (Estoup \& Guillemaud 2010), contribute to numerous aspects of non-native species management, including the assessment of risks (e.g. ecological and evolutionary effects on recipient ecosystems) and benefits to the society (Gozlan 2008), as well as the development (or enhancement) of nonnative species policy and legislation. A major difficulty in assessing the origin of successful invasions and their impacts on ecosystems is that biological invasions are a multi-step and trans-disciplinary process, which involves population, community, evolutionary and physiological biology during the various invasion phases - introduction, establishment, dispersal and impact steps (Moyle \& Light 1996).

Many empirical tools have been applied to the field of biological invasions, but few have coped with these multi-step and trans-disciplinary aspects. For instance, stable isotope analyses (SIA) have proven useful in deciphering the trophic interactions between native and non-native species, which has provided insights into the population and community impacts of nonnative species in freshwater ecosystems (Vander Zanden et al. 1999; Cucherousset et al. 2007, 2012). However, SIAs cannot be used to quantify the evolutionary impacts of non-native species on the native fauna, or to establish routes of invasion. Nevertheless, there are specific molecular tools for investigating each phase of biological invasions from both an ecological and evolutionary perspectives (Fig. 1).

Recent technical developments in molecular tools, such as next-generation sequencing or gene expression analyses, coupled to a decrease in the cost of more classical methodologies such as microsatellite genotyping, have largely contributed to the versatility of these tools (DeYoung \& Honeycutt 2005; Selkoe \& 


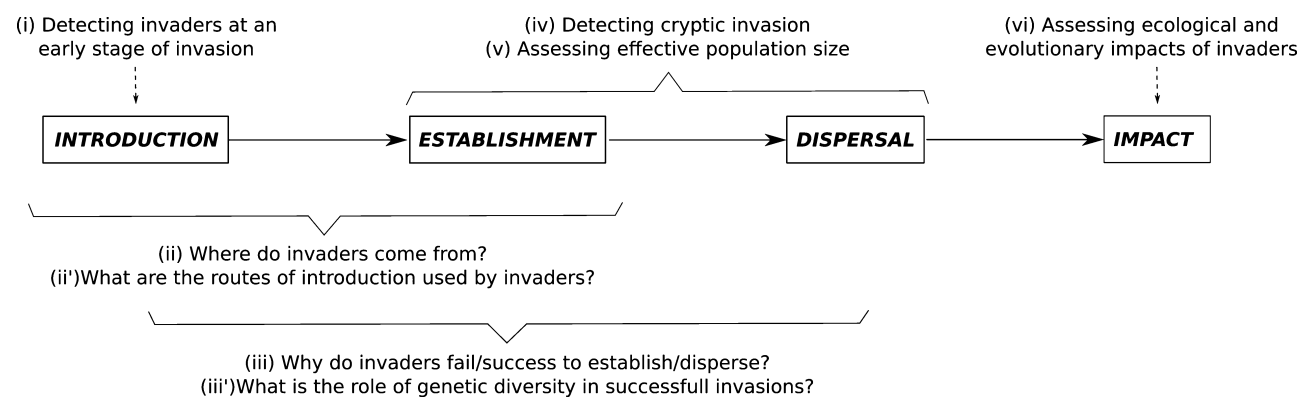

Figure 1. Flowchart showing the various questions related to biological invasions that can be answered using molecular tools, allowing investigation of biological invasions from as species introduction through establishment and impact. Questions highlighted in the flowchart (from ' $\mathrm{i}$ ' to 'vi') are developed in the main text.

Toonen 2006; Bonneaud et al. 2008; Ellegren \& Sheldon 2008). Accordingly, a number of recent reviews have emphasised the usefulness of molecular tools for answering specific questions related to the sources and routes of invasion (Estoup \& Guillemaud 2010; Geller et al. 2010), the establishment success of non-native species (Hänfling 2007; Miura 2007), as well as the detection of cryptic non-native species (Miura 2007; Geller et al. 2010).

The aim of this review is to provide an overview of the molecular techniques available and how these can be used to answer specific questions related to biological invasions, with particular emphasis on freshwater ecosystems, which are particularly susceptible to the consequences of biological invasions (Copp et al. 2005; Dudgeon et al. 2006; Lawler et al. 2006; Gozlan et al. 2010; Cucherousset \& Olden 2011). Contrary to previous review papers (Hänfling 2007; Miura 2007; Estoup \& Guillemaud 2010; Geller et al. 2010), an exhaustive approach has been adopted to examine the several facets of biological invasions, mainly, but not exclusively, focusing on fish, and how these can be investigated using either classical or novel molecular techniques (Fig. 1). First, examples are considered regarding the early detection of nonnative species as well as the identification of their origins (source locations), the invasion pathways and introduction vectors used. Secondly, the traits and processes underlying successful invasions are examined using examples that emphasise the role of genetic diversity in the successful establishment/dispersal of non-native species. Thirdly, the uses of molecular tools to detect cryptic non-native species and to estimate the effective size of established non-native populations are discussed. Finally, the usefulness of molecular tools to assess the ecological and evolutionary consequences of biological invasions is reviewed.

\section{The use of molecular tools in invasion biology: case studies}

\section{Detecting invaders at early stages of invasion}

Early detection of a non-native species is of prime importance for preventing the species' establishment and potential dispersal. The eradication and/or control of non-native species is indeed more efficient, and less costly, when the species is present in very low densities and not yet established (Gozlan et al. 2010). However, species at low density generally require intensive sampling efforts to be detected. In freshwater ecosystems, molecular tools are an alternative (or at least complementary approach) to traditional sampling methods for detecting species invasion. Recent methods, based on so-called environmental DNA (eDNA), are particularly attractive as these allow the detection of species from the collection and identification of genetic material found in water, soil or faecal samples (Ficetola et al. 2008). Historically, this framework was developed to estimate the richness of micro-organisms in open environments such as soils or seawaters. However, it has recently been applied successfully to freshwater organisms such as fish and amphibians, whereby the small DNA fragments continuously secreted or excreted in the water by these organisms (e.g. mucus, faecal matter) are detected and amplified. The species can be subsequently identified using specific primers (Fig. 2).

This novel method was first applied to detect the invasive American bullfrog, Rana catesbeiana (Shaw), in Western Europe (Ficetola et al. 2008). Using both laboratory and field experiments to validate the approach, the authors were able to detect the presence of the frog in small ponds $\left(1000-10000 \mathrm{~m}^{2}\right)$ even when at very low density (1-2 adults censored per pond). Small $(15 \mathrm{~mL})$ water samples were collected from three 


\section{Environmenal DNA monitoring}

Collection of water samples

$(15 \mathrm{~mL}-2 \mathrm{~L})$

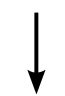

Water filtration or centrifugation (to concentrate the DNA fragments)

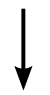

DNA extraction

(classical or water-specific extraction)

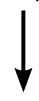

DNA amplification through PCRs

(in general specific primers of mitochondrial genes are used)

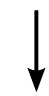

Detection of PCR products

(on agarose gel in general - sequencing if necessary)

Figure 2. Flowchart describing the main steps for detecting the presence/absence of a non-native species using environmental DNA (eDNA), which is based on the sampling, detection and identification of a species from residual DNA fragments extracted from water samples and identified using PCRs and appropriate genetic markers.

different points in each pond, and the DNA contained in these samples was extracted and amplified using a specific mitochondrial primer (Ficetola et al. 2008: see also Fig. 2) from most of the samples, indicating that only a few water samples were required to detect the invasive species' presence.

This approach has also been applied to the detection of invasive Asian carp species [Hypophthalmichthys molitrix (Valenciennes) and Hypophthalmichthys nobilis (Richardson)] in water courses of North America (Jerde et al. 2011). As in Ficetola et al. (2008), the authors designed specific primers amplifying a short region of the mitochondrial D-loop region. These primers were then applied to the DNA extracted from 2-L water samples collected from a canal system that connects the Mississippi River basin with Lake Michigan through which Asian carp species could invade the Great Lakes. The eDNA technique was able to detect the presence of the Asian carp species where intensive traditional surveys using electric fishing failed to do so, indicating that invasion of the Great Lakes is likely to have already occurred. In addition, catch-perunit-effort results of traditional surveys and the quantities of eDNA were compared, demonstrating that eDNA could also provide an indication of the abundance albeit with some limitations (Jerde et al. 2011).
Managing non-native species is always a great challenge, and care must be taken when interpreting outputs from eDNA surveys. Indeed, contrary to traditional sampling techniques, both false positive (type I errors) and false negative (type II errors) are possible when using DNA-based methods (see Darling \& Mahon 2011 for more details), that is assuming the null hypothesis that the target species is absent from the system being investigated. Although technical and procedural precautions exist to limit such errors (Jerde et al. 2011), the possibility of false positives and negatives needs to be accounted for when management decisions are being made. Despite such risks, these two studies demonstrated that the use of eDNA is effective, technically easy to develop and highly cost-effective (specific markers detectable using agarose gel). As such, this approach could rapidly become routine for the survey of non-native species in freshwater ecosystems, even in very large water bodies such as lakes.

\section{Where do invaders come from? What are their routes of invasion?}

Isolating the geographic origin and the pathways followed by species or their propagules to invade a new region (i.e. routes of invasion) are two related questions that have very important applied implications (Mack et al. 2000). Particularly, the identification of the origins (or sources) of invaders and the routes of invasion is of prime importance for designing strategies (e.g. monitoring, quarantine procedures) to prevent, reduce and/or control invasions (Mack et al. 2000; Gozlan et al. 2010). Molecular tools are an insightful means to investigate these two issues (invasion sources, routes of invasion) as they permit the quantification of genetic relationships (or distance) between source and invaded populations as well as to infer the evolutionary scenarios following invasion (Estoup \& Guillemaud 2010). In general, either mitochondrial or microsatellites markers are used, depending on the time elapsed since invasion (see Miura 2007; Muirhead et al. 2008; Estoup \& Guillemaud 2010; Vidal et al. 2010). An empirical example is provided here with the objectives to: (1) isolate the source(s) of introduction of a rainbow trout, Oncorhynchus mykiss (Walbaum) population established in the Saint Lawrence Estuary (Quebec, Canada); and (2) determine the range of expansion of this newly established population (Thibault et al. 2009).

Rainbow trout originates from western North America and is one of the most widely introduced fish species worldwide (Rahel 2007; Crawford \& Muir 2008). It can have severe ecological and evolutionary 
consequences on native fish populations (Volpe et al. 2001; Simon \& Townsend 2003; Blanchet et al. 2007). In Eastern Canada (Great Lakes, Western Quebec, Maritime provinces), rainbow trout has been stocked in large quantities for fishery, angling and/or aquaculture purposes since the late 1890s. Some populations have rapidly established in these regions (mainly in Lake Ontario, Lake Memphremagog, the Saint Lawrence River near Montreal and in the Maritime province: Fig. 3), and more recently, new populations have been discovered outside these regions (i.e. Eastern Quebec, Fig. 3), notably in rivers containing native Atlantic salmon, Salmo salar L. Microsatellites markers combined with population assignment tests (Piry et al. 2004) were used to demonstrate that these new populations derive mostly from naturalised populations established in Lake Ontario and to a lesser extent from Lake Memphremagog (Thibault et al. 2009).

The populations established in the Maritime province, as well as the hatchery fish stocked annually in many drainage basins by local and private anglers, contributed little to the ongoing invasion process. These results suggest that rainbow trout followed an upstream-to-downstream route along the Saint Lawrence corridor to invade these new river catchments (Fig. 3). By refining assignment analyses, the dispersion mode of rainbow trout along this route was documented (Thibault et al. 2009), revealing that rainbow trout followed a two-step dispersal pattern: the source population from the upstream section (Lake

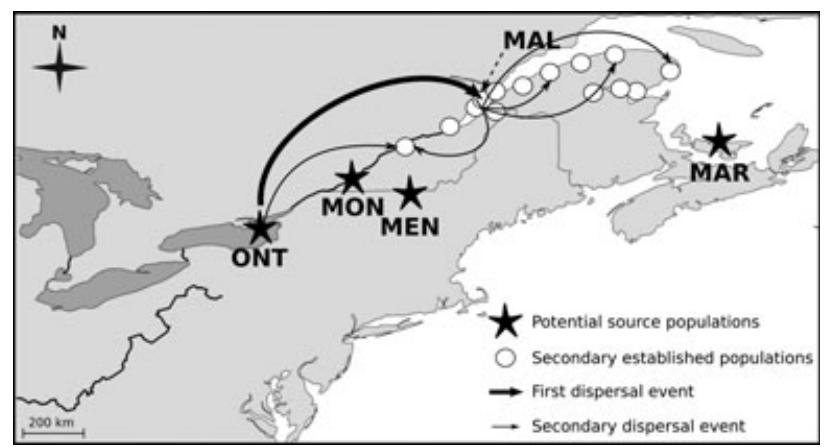

Figure 3. Map describing the invasion route of rainbow trout (Onchorynchus mykiss) in the Saint Lawrence Estuary (Canada). Stars correspond to locations where rainbow trout where first introduced and established self-sustaining populations (ONT, Lake Ontario; MON, Montreal; MEN, Lake Memphremagog; MAR, Maritime Province), with white circles indicating locations where rainbow trout have been detected recently (i.e. after the 1980s) and therefore indicative of populations established in the Malbaie river (MAL, first dispersal event) by emigrants from ONT, followed by secondary dispersal events all along the Saint Lawrence river system (adapted from Thibault et al. 2009).
Ontario) first provided propagules that led to the establishment of a few (secondary) new self-sustaining populations in salmon rivers (mainly the Malbaie River: Fig. 3), which then produced vagrants that eventually colonised neighbouring rivers. This process also involved some invaders still dispersing from the upstream (Lake Ontario) populations. By contrast to a classical stepping-stone model, the dispersion was not constrained to adjacent habitat, but was targeted towards highly favourable habitat in which offspring are produced to disperse into new habitats (Thibault et al. 2009).

Thibault et al. (2009) provided insightful details on the sources, routes and modes of rainbow trout invasion of Eastern Canada and these have several management implications, such as the possibility of reducing the effective population size of newly established populations that now serve as source populations. From a management point of view, such tools can therefore be highly effective provided that all potential sources of introduction have been sampled a priori, otherwise this could result in sub-optimal management plans. As discussed elsewhere (Estoup \& Guillemaud 2010), the development of new analytical tools, such as Approximate Bayesian Computation (Beaumont et al. 2002), is particularly valuable for drawing inferences, and comparing scenarios, about the invasion history of nonnative species. Future studies should, therefore, provide new insights about the environmental and genetic determinants of successful invasions.

\section{Why do invaders fail or succeed to establish and spread? What is the role of genetic diversity in successful invasions?}

A major objective of invasion biology is to understand why some species succeed in establishing new populations outside their native range and others fail (GarcíaBerthou 2007). In general, biological characteristics such as competitive ability, fecundity or environmental tolerance are invoked to explain invasion success (Kolar \& Lodge 2001). However, the ability to invade new environments can vary among populations of a species (Kelly et al. 2006), and genetic variability could be the crucial determinant of a population's ability to invade a new environment (Roman \& Darling 2007; Facon et al. 2008). Indeed, genetic variability is the substance for populations to adapt (through natural selection) to new ecological conditions encountered in new environments (Roman \& Darling 2007). Paradoxically, non-native species are expected to undergo a genetic bottleneck during introduction, hence resulting in a severe loss of genetic diversity. 
Several mechanisms may impede this expected loss of genetic diversity (reviewed by Hänfling 2007). Among them, multiple introduction events (i.e. introduction of genetically divergent source populations in the same geographical area) have been demonstrated to dilute substantially, and even overshadow, these founder effects (Kolbe et al. 2004). As detailed in the previous section, molecular tools can be used to identify the source population, and following from this, to determine whether or not the established population has lost genetic diversity during the invasion. If not, then the contribution of multiple introductions can be determined. A number of studies have tested whether established fish populations are genetically less diverse relative to source population(s) to investigate the role of multiple introductions in successful invasions (Hänfling 2007). However, there is no clear consensus from these studies because the results are heterogeneous. For instance, most invasive populations of topmouth gudgeon, Pseudorasbora parva (Temminck and Schlegel), have a higher genetic diversity (mitochondrial genes) than putative, native, source populations (Simon et al. 2011), and this has been attributed to multiple invasions of a single European location by several source populations from which secondary dispersal of the species led to invasions elsewhere (Simon et al. 2011). By contrast, a study of genetic traits of bluegill sunfish, Lepomis macrochirus Rafinesque, populations in Japan using microsatellite markers showed that few individuals have been imported to a single location from which they subsequently dispersed throughout the country (Kawamura et al. 2010). Most of these established populations displayed a relatively low level of genetic diversity compared with the source population (Kawamura et al. 2010). The first example illustrates a case where genetic admixture may have increased the genetic diversity of the invading population, hence its invasive potential, whereas the second example suggests that this successful establishment pattern cannot be applied to all invaders.

The latter example also suggests that population parameters other than neutral genetic diversity per se need to be considered to understand invasion success. As suggested by Kawamura et al. (2010), sufficient additive genetic variance should be present for (local) adaptation to occur despite low neutral genetic diversity, and this has been reported in fish species extending their range, such as European grayling, Thymallus thymallus L., populations in Northern Europe (Koskinen et al. 2002). Alternatively, phenotypic plasticity in introduced populations appears to be another important trait to consider. For instance, plasticity in life-history strategies of brown trout, Salmo trutta L., was found to provide a better explanation of the species invasiveness in Patagonian rivers than genetic diversity (Valiente et al. 2010).

To summarise, genetic diversity has been advocated as being a crucial factor in determining the invasion success of non-native species (Roman \& Darling 2007). However, empirical results are still contradictory, indicating that more efforts should be devoted to understanding the link between genetic diversity and invasiveness. Future studies should simultaneously consider genetic diversity and variance in adaptive traits (Kawamura et al. 2010; Valiente et al. 2010) so as to understand how low genetic diversity in introduced populations can be a limitation for local adaptation and to tease apart the role of phenotypic plasticity in invasion success (Lee 2002). In addition, almost all previous studies have used neutral markers (e.g. microsatellites, mitochondrial genes) to measure genetic diversity in invading populations. The comparison of genetic diversity measured with neutral and non-neutral markers, such as MHC or protein-coding loci (Valiente et al. 2010), should provide new insights into the evolution of neutral and non-neutral genetic diversity during and after introductions. Finally, nongenetic processes such as epigenetic mechanisms might be involved in the success of populations in invading new areas (Danchin et al. 2011). New molecular tools are available to detect epimutation or epigenetic differences between populations (Bossdorf et al. 2008), and such tools should provide unexplored insights about the evolutionary processes that allow populations to invade new areas.

\section{Detecting cryptic non-native species}

Most fish species that invade new environments are well described phenotypically and taxonomically. However, there are many other freshwater organisms (e.g. crustaceans, molluscs, parasites) for which morphological identification is difficult, if not impossible. These species are referred to as cryptic species (a single morpho-species that comprises one or more biological species: Bickford et al. 2007). These morphologically indistinguishable species can be introduced without human recognition of their genetic (and ecological) uniqueness, leading to a cryptic invasion (Miura 2007). Cryptic invasions can be successfully monitored using molecular markers, as, by definition, cryptic species are genetically unique. The problem of cryptic invasion has been largely recognised in marine ecosystems (Geller et al. 2010), but remains mostly ignored in freshwater ecosystems (but see Stepien \& Tumeo 2006; 
Markova et al. 2007; Forro et al. 2008). A notable example in freshwater ecosystems concerns the detection and monitoring of dreissenid mussels [Dreissena polymorpha (Pallas) and Dreissena bugensis (Andrusov)] in the western United States of America, as this monitoring allowed identification for not only adults but also larvae, which is often very complicated for those organisms (Hickey 2010). Cryptic invasion is a major ecological and evolutionary issue to consider and even fish can be affected by cryptic invasions.

Surveys found an unexpected invasion of European bullhead, Cottus gobio L., in the lower River Rhine (Germany), with most individuals being found in unusual habitats such as large stagnant water bodies where water temperature and turbidity are high (Nolte et al. 2005). As European bullheads are generally adapted to cold upstream sites, this invasion highlighted a previously unreported tolerance to warm and turbid waters (but see Faulkner \& Copp 2001; Copp et al. 2002; Knaepkens et al. 2006). Two scenarios could explain the origin of these fish. The first was that bullhead has persisted in the lower Rhine at very low density and recently began to recolonise (and expand) their range following recent improvements of water quality. The second was in terms of a recent invasion from a bullhead lineage originating from the Scheldt river basin (Germany), which recently became connected to the Rhine system via canals. Nolte et al. (2005) tested these two scenarios by combining mitochondrial and single nucleotide polymorphism markers within a phylogeographical framework. The authors demonstrated that the invasive lineage was a hybrid between two old lineages from the Scheldt and the Rhine drainages. Importantly, morphological analyses demonstrated that this new lineage had a unique ecological potential allowing the colonisation of new habitats that were previously not used by bullheads.

The above example shows that the translocation and mixing of lineages can have unpredictable effects, with hybridisation modifying colonisation ability of the species. Without molecular tools, these cryptic invasions would be difficult to assess, and it is very likely that the number of non-native (either translocated or exotic) species/lineages in freshwater ecosystems is highly underestimated. Similar patterns have been described in other fish groups (Stepien \& Tumeo 2006; Neilson \& Stepien 2009). Furthermore, recent molecular studies have revealed unexpected genetic diversity in many freshwater fishes (including European species), suggesting the existence of cryptic species in fish (Costedoat et al. 2006). These findings call for a precautionary approach when managing the intentional translocation between river basins of spe- cies that have been described only using morphological approaches. In such cases, a genetic identification should systematically be undertaken to ensure that cryptic species are not involved in the translocation process.

\section{Assessing invasive population size}

Once a non-native species has become established, quantifying population size is a prerequisite to successful eradication or control (Simberloff 2003, 2005). Population size can be estimated using either census size $\left(N_{\mathrm{c}}\right.$ : number of individuals in an area) or effective size ( $N_{\mathrm{e}}$ : number of breeding individuals). $N_{\mathrm{c}}$ is an essential parameter for predicting the potential ecological effects of a non-native species on the recipient ecosystem and can be assessed using a variety of direct methods (e.g. electric fishing, trapping, trawling, netting, capture-mark-recapture approaches) provided that they have been appropriately calibrated (Nielsen \& Johnson 1983). $N_{\mathrm{e}}$ is much more difficult to quantify using direct methods, but is essential to discern the dynamic of non-native populations and their colonisation potential (Aspi et al. 2006; Luikart et al. 2010). Changes in $N_{\mathrm{e}}$ leave fingerprints on the genetic make-up of populations, and several methods to estimate $N_{\mathrm{e}}$ using changes in various genetic estimators such as heterozygosity, linkage disequilibrium and allele frequencies have been developed and implemented in user-friendly softwares. In general, these methods use highly polymorphic markers such as microsatellites, and they are based on either stationary (single-sample) or temporal (multiple-sample) sampling approaches (see review by Luikart et al. 2010).

Although these genetic methods are routinely used to estimate $N_{\mathrm{e}}$ in endangered or threatened fish populations (Fiumera et al. 2000; Alo \& Turner 2005), there are apparently no studies that have used molecular tools to estimate contemporary $N_{\mathrm{e}}$ in nonnative fish populations. However, using temporal data could be useful for understanding the population dynamics of non-native species during the invasion process (notably in species with chaotic population cycles; Cucherousset et al. 2006), and hence to establish management schemes that adequately fit these dynamics. However, recent studies suggest that genetic estimation of $N_{\mathrm{e}}$ could also provide accurate estimates of $N_{\mathrm{c}}$. For instance, Osborne et al. (2010) demonstrated that $N_{\mathrm{e}}$ (calculated using genetic methods) in Pecos bluntnose shiner, Notropis simus pecosensis Gilbert and Chernoff, was positively associated to $N_{\mathrm{c}}$, calculated using traditional monitoring data. 
Similarly, Blanchet et al. (2010) found a strong and positive relationship between $N_{\mathrm{e}}$ and $N_{\mathrm{c}}$ across four cyprinid fish species. It is noteworthy that the relationship between $N_{\mathrm{e}}$ and $N_{\mathrm{c}}$ cannot be generalised across species, as it is tightly linked to the reproductive strategies of species, for example, strong variance in reproductive success among individuals (Luikart et al. 2010). If fish biologists generally used physical tags to acquire estimates via a capture-mark-recapture approach, then molecular markers (e.g. microsatellites) are suited to identify fish, which constitutes a promising alternative to physical tags (Andreou et al. 2012). Using genetic markers might be particularly well suited for tagging very small fish (either species or life stages), whilst avoiding the problem of tag loss. The use of individual DNA identification with capture-markrecapture techniques is common with large mammals (Luikart et al. 2010) and is likely to become more popular in fish biology with the development of cheaper molecular techniques.

Assessing changes in the $N_{\mathrm{e}}$ of non-native species is important to understand and predict their colonisation patterns, and hence to control their future expansion. Several molecular methods have been developed to help ecologists estimate both $N_{\mathrm{e}}$ and $N_{\mathrm{c}}$ (Luikart et al. 2010) from wild populations. Although care must be taken with the sampling design used to infer $N_{\mathrm{e}}$ and $N_{\mathrm{c}}$ from molecular tools and when interpreting outputs from such analyses (Luikart et al. 2010), it is argued that invasion biologists should now master these tools to gain insight into the biology of non-native species.

\section{Assessing ecological and evolutionary impacts of invaders}

Assessing the ecological and evolutionary impacts of non-native species is of major interest to environmental managers and conservationists, notably to provide an objective risk assessment (Copp et al. 2009). Molecular tools can be used to assess the ecological impacts of non-native species by establishing trophic links with native species, as well as the changes in $N_{\mathrm{e}}$ of native species associated with the invasion. At the evolutionary level, molecular tools can be used to understand patterns of adaptation in native and nonnative species. Although molecular tools are particularly valuable to detect hybridisation between native and non-native species (e.g. Costedoat et al. 2007; Dubut et al. 2010), aspects related to hybridisation will not be discussed here as detailed information is available elsewhere (Allendorf et al. 2001; Costedoat et al. 2007).
Trophic links The recent development of DNA barcoding approaches (Hebert et al. 2003) has greatly facilitated the determination of animal diet, using either faeces or gut contents. However, most of these PCR-based techniques have been developed with terrestrial animals and have rarely been applied to freshwater fish (Deagle et al. 2005; Casper et al. 2007). Recently, a cheap, non-lethal and simple PCR-based method has been developed for the identification of prey contained in the faeces of freshwater fish using DNA barcoding (Corse et al. 2010) using specific primers (for $18 \mathrm{~S}$ rDNA) to generate prey-specific amplicons from a faecal DNA matrix (Fig. 4). These prey-specific amplicons have unique sizes, hence allowing a rapid discrimination using Agarose gel lane, therefore reducing the financial costs. Specific primers were designed for up to 34 prey groups (the barcode library) typical of most rivers worldwide (i.e. from Chlorophyta to various Arthropoda families), hence making this method directly available to fish ecologists. Each of these prey groups was also associated to a meso-habitat (bio-habitat library) to provide information on both diet and the habitat use of consumers.

This method has been applied to discriminate the diet and habitat use of three sympatric cyprinid species [Chondrostoma nasus (L.), Chondrostoma toxostoma (Vallot), Barbus barbus (L.)] in a French drainage basin, where one of the species (C. nasus) is invasive (Corse et al. 2010). They were able to provide a very

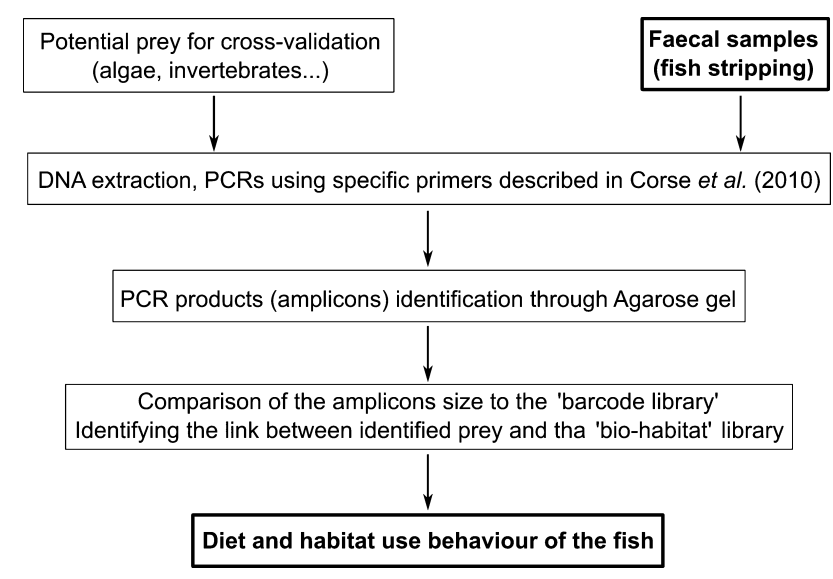

Figure 4. Flowchart describing the PCR-based method of Corse et al. (2010) for identifying the prey consumed by fish from DNA fragments contained in the fish faeces using primers that are highly specific to the potential prey that are present on the ecosystem. This method is costeffective as the specificity of the primers allows using agarose gel for prey identification. In parallel with the barcode library, which allows identifying prey, a bio-habitat library was established to allow inferences to be made as regards the type of foraging habitat. 
fine discrimination between these bottom feeding fish along with new insights into their ecological and competitive interactions. More generally, such methods are an ideal complement to other approaches, such as stable isotope analysis, to infer the diet of nonnative species (Cucherousset et al. 2012). Indeed, PCRbased methods provide information at a very fine taxonomic level, which is often impossible using stable isotopes. In addition, these methods are based on an instantaneous snapshot and capture short-term diet variation. This method measures what has been captured by fish, but not what has been assimilated. Hence, this methodology is complementary of stable isotope analyses and could replace stomach content analyses that are often labor intensive.

Changes in effective population size of native species As stated above, molecular tools can be used to infer contemporary $N_{\mathrm{e}}$ in the wild. Several methods have been developed to infer temporal changes in $N_{\mathrm{e}}$, notably population genetic bottlenecks (i.e. when a population undergoes a drastic and rapid decrease in $N_{\mathrm{e}}$ ). In the context of biological invasions, it is expected that native populations decrease drastically in population size if, for instance, a predator is introduced. Such population effects might therefore be detected and quantified using molecular tools.

After a bottleneck event, the allelic diversity is expected to decline faster than heterozygosity. Thus, the observed heterozygosity in a bottlenecked population should be larger than the heterozygosity expected from the observed allele number at mutation-drift equilibrium (Cornuet \& Luikart 1996). One of the most widely used methods is based on this assumption, and it has been developed into a software package: BOTTLENECK (Cornuet \& Luikart 1996). Although this method can detect the presence of recent genetic bottlenecks (Cornuet \& Luikart 1996), it does not provide an estimate of the time elapsed since the bottleneck occurred nor the intensity of the bottleneck. These limitations have been overcome with the development of more calculation-intensive methods (Storz \& Beaumont 2002). With these methods based in a hierarchical Bayesian model, which is based on a coalescent framework, changes in effective population size such as expansions or contractions can be detected, quantified and dated. Assuming a stable, closed population of ancestral size $\left(N_{1}\right)$ increases or decreases exponentially to its current size $N_{0}$ over a time interval $T_{\mathrm{A}}$ (in years), several parameters $\left(\mathrm{N}_{1}, \mathrm{~N}_{0}\right.$ and $\left.\mathrm{T}_{\mathrm{A}}\right)$ can be inferred using Markov Chain Monte Carlo techniques. Contrary to more conventional methods, all genetic information is used to infer these parameters (Storz \& Beaumont 2002).

Methods quantifying changes in $N_{\mathrm{e}}$ are routinely used in fish ecology, notably to evaluate how human pressures such as habitat fragmentation can affect effective population size of populations. Surprisingly, there are few studies that use these potentially powerful methods to evaluate how the introduction of nonnative species affects the $N_{\mathrm{e}}$ of native species. However, it is noteworthy that these techniques are constrained by some limitations. For instance, there is a trade-off between the intensity of the changes in $N_{\mathrm{e}}$ and the time before their statistical detection; the stronger the change in $N_{\mathrm{e}}$, the quicker the detection (Cornuet \& Luikart 1996). Such trade-offs need to be accounted for when interpreting outputs of change in $N_{\mathrm{e}}$ analyses, notably in the case of negative results that can be false negative (type II errors).

Evolution and adaptation of native and nonnative populations When non-native species invade a new environment, they may experience new selective pressures and/or act as a novel agent of selection on native flora and fauna. Therefore, an important issue in biological invasions is to understand the underlying (rapid) process of adaptation of both native and non-native species (Lee 2002; Strauss et al. 2006; Suarez \& Tsutsui 2008). This can be investigated using molecular tools, generally combined with phenotypic data.

The developments of high-throughput sequencing and of tools related to gene expression (e.g. microarrays) are well suited to study rapid genomic adaptation in native and non-native species. Phenotypic plasticity is an important process allowing native species to adjust their behaviour to non-native competitors or predators quickly. For instance, the introduction of rainbow trout was observed to affect the behavioural strategy of the native Atlantic salmon in Canadian rivers through competition (Blanchet et al. 2007). Specifically, the social dominance within groups of Atlantic salmon was disrupted when competing with rainbow trout. To identify the genetic and molecular causes of this loss of dominance (hence, the genes potentially under selection), micro-arrays were used to compare the genome-wide gene transcription profiles in brains of dominant vs subordinate Atlantic salmon in the presence or absence of rainbow trout (Roberge et al. 2008). A total of 73 genes (over the 16006 clones on the micro-array) displayed significant differences in expression between dominant and subordinate salmon when rainbow trout was absent. None of the genes displayed differences in gene expression when rainbow 
trout was present, suggesting that the disruption of dominance hierarchies was accompanied by significant changes in gene expression (Roberge et al. 2008). Among these 73 genes, most were over-expressed in the brains of dominant salmon and associated with protein turnover, neuronal structural change and oxygen transport. Roberge et al. (2008) demonstrated a close interplay between behavioural plasticity induced by non-native species and gene transcription, which helps understanding the molecular mechanisms allowing native species to adapt to biological invasions. Similarly, high-throughput sequencing is likely to become a crucial tool to investigate the genomic basis (which part of the genome is specifically targeted by natural selection) of rapid adaptation in native and non-native species. Although such technologies have been used in fish ecology (Renaut et al. 2011), examples are lacking in the context of biological invasions.

Alternatively, more traditional approaches have been used, such as in the study of divergence in neutral vs quantitative traits (Fst vs Qst; Whitlock 2008) between translocated populations of European grayling to infer the role of natural selection vs genetic drift in explaining evolutionary patterns (Koskinen et al. 2002). It is generally expected in these approaches that pair-wise population differentiations (measured using quantitative traits such as growth, fecundity or behaviour) should be significantly different, and in general greater than those measured using neutral traits (mainly using microsatellites markers) if natural selection is the main driver. Koskinen et al. (2002) measured a series of phenotypic traits using a common garden approach in several populations that were founded 80 120 years ago. For most of these traits, differentiation among populations was significantly greater than that measured using a set of microsatellites. This indicated that natural selection was the main process explaining contemporary evolution in the recently founded populations. The number of founder individuals per translocated population was extremely low, indicating that natural selection can also be efficient even when the initial gene pool is restricted (Koskinen et al. 2002).

Non-native species evolve (and eventually adapt) to the novel, invaded environment. The processes underlying evolution and adaptation (sensu lato) of native and non-native species are various and can range from a neutral (genetic drift) to a targeted (natural selection) process. Therefore, biological invasions provide insightful experiments about rapid evolution in the wild (Strauss et al. 2006; Suarez \& Tsutsui 2008), and molecular tools are, in this context, of prime importance.

\section{Conclusions}

This review has highlighted that the plurality of the molecular approach makes it attractive (and complementary) for biologists working on biological invasions. However, as discussed, many possibilities still remain unexplored or weakly considered, and this review will hopefully motivate invasion biologists to fill these gaps. For instance, using new sequencing technologies or gene candidate approaches (Ellegren \& Sheldon 2008), future studies should be designed to provide a better understanding of the processes (e.g. natural selection, gene-environment interaction, mutation, genetic drift) that permit invading populations to adapt to their new environments and invaded populations to the new fish community composition. From a more applied point of view, more studies should use eDNA, not only to detect the presence/absence of a given fish species, but also to quantify its abundance and to characterise the entire fish community. Environmental DNA monitoring has the potential to outperform conventional monitoring approaches, but this will be possible only if carefully designed studies continue to validate this approach and provide a comprehensive and standardised protocol (Darling \& Mahon 2011). Similarly, studies of diet and trophic interactions should take advantages of methods such as the growing accessibility of DNA barcoding databanks (Corse et al. 2010). Again, the immediate need is for methodological developments to provide invasion biologists with standardised and user-friendly protocols.

Aside from the research perspective, a challenge for the next few years will be to continue working on analytical solutions for collecting data using molecular tools. For instance, bio-informatics needs to be developed to ensure efficient analyses of data gathered from high-throughput sequencing technology. Similarly, Bayesian statistics have proven insightful for inferring population parameters such as changes in effective population size or dispersal rates (Beaumont \& Rannala 2004); new statistical and theoretical tools need to be developed to maximise the amount of precise information that can be derived from such data.

In summary, the next decade will probably be that of the molecular invasion biologist, as many insights can be gained from molecular tools. At the same time, there is a need to continue developing methodological and analytical frameworks (Beaumont et al. 2002; Corse et al. 2010) that allow biologists to synthesise precise and informative population parameters from genetic data. 


\section{Acknowledgments}

I sincerely thank the organisers of the NeoFishMed workshop for inviting me and for the insightful discussion about the consequences of biological invasions on freshwater ecosystems. I thank two referees for the constructive comments they provided. I also thank J. Cucherousset and R. Michniewicz for commenting on earlier drafts of this paper.

\section{References}

Allendorf F., Leary R., Spruell P. \& Wenburg J. (2001) The problems with hybrids: setting conservation guidelines. Trends in Ecology and Evolution 16, 613-622.

Alo D. \& Turner T.F. (2005) Effects of habitat fragmentation on effective population size in the endangered Rio Grande silvery minnow. Conservation Biology 19, 138-1148.

Andreou D., Vacquie-Garcia J., Cucherousset J., Blanchet S., Gozlan R.E. \& Loot G. (2012) Individual genetic tagging for teleost fishes: an empirical validation and a guideline for ecologists. Journal of Fish Biology 80, 181194.

Aspi J., Roininen E., Ruokonen M., Kojola I. \& Vilà C. (2006) Genetic diversity, population structure, effective population size and demographic history of the Finnish wolf population. Molecular Ecology 15, 1561-1576.

Beaumont M.A. \& Rannala B. (2004) The Bayesian revolution in genetics. Nature Reviews Genetics 5, 251-261.

Beaumont M.A., Zhang W.Y. \& Balding D.J. (2002) Approximate Bayesian computation in population genetics. Genetics 162, 2025-2035.

Bickford D., Lohman D.J., Sodhi N.S., Ng P.K.L., Meier R., Winker K. et al. (2007) Cryptic species as a window on diversity and conservation. Trends in Ecology and Evolution 22, 148-155.

Blanchet S., Loot G., Bernatchez L. \& Dodson J. (2007) The disruption of dominance hierarchies by a non-native species: an individual-based analysis. Oecologia 152, 569-581.

Blanchet S., Rey O., Etienne R.S., Lek S. \& Loot G. (2010) Species-specific responses to landscape fragmentation: implications for management strategies. Evolutionary Applications 3, 291-304.

Bonneaud C., Burnside J. \& Edwards S.V. (2008) High-speed developments in avian genomics. BioScience 58, 587-595.

Bossdorf O., Richards C.L. \& Pigliucci M. (2008) Epigenetics for ecologists. Ecology Letters 11, 106-115.

Casper R.M., Jarman S.N., Gales N.J. \& Hindell M.A. (2007) Combining DNA and morphological analyses of faecal samples improves insight into trophic interactions: a case study using a generalist predator. Marine Biology 152, 815-825.
Copp G.H., Doherty S., Faulkner H., Watkins M.S. \& Majecki J. (2002) Diel drift behaviour of fish eggs and larvae, in particular barbel, Barbus barbus (L.), in an English chalk stream. Fisheries Management and Ecology 9, 95-104.

Copp G.H., Bianco P.G., Bogutskaya N.G., Erős T., Falka I., Ferreira M.T. et al. (2005) To be, or not to be, a nonnative freshwater fish? Journal of Applied Ichthyology 21, 242-262.

Copp G.H., Vilizzi L., Mumford J., Fenwick G.V., Godard M.J. \& Gozlan R.E. (2009) Calibration of FISK, an invasive-ness screening tool for non-native freshwater fishes. Risk Analysis 29, 457-467.

Cornuet J.M. \& Luikart G. (1996) Description and power analysis of two tests for detecting recent population bottlenecks from allele frequency data. Genetics 144, 2001-2014.

Corse E., Costedoat C., Chappaz R., Pech N., Martin J. \& Gilles A. (2010) A PCR-based method for diet analysis in freshwater organisms using $18 \mathrm{~S}$ rDNA barcoding on faeces. Molecular Ecology Resources 10, 96-108.

Costedoat C., Chappaz R., Barascud B., Guillard O. \& Gilles A. (2006) Heterogeneous colonization pattern of European cyprinids, as highlighted by the dace complex (Teleostei: Cyprinidae). Molecular Phylogenetics and Evolution 41, 127-148.

Costedoat C., Pech N., Chappaz R. \& Gilles A. (2007) Novelties in hybrid zones: crossroads between population genomic and ecological approaches. PLoS ONE 2, e357.

Crawford S. \& Muir A. (2008) Global introductions of salmon and trout in the genus Oncorhynchus: 1870-2007. Reviews in Fish Biology and Fisheries 3, 313-344.

Cucherousset J. \& Olden J.D. (2011) Ecological impacts of non-native freshwater fishes. Fisheries 36, 215-230.

Cucherousset J., Paillisson J.M., Carpentier A., Eybert M.C. \& Olden J.D. (2006) Habitat use of an artificial wetland by the invasive catfish Ameiurus melas. Ecology of Freshwater Fish 15, 589-596.

Cucherousset J., Aymes J.C., Santoul F. \& Céréghino R. (2007) Stable isotope evidence of trophic interactions between introduced brook trout (Salvelinus fontinalis) and native brown trout (Salmo trutta) in a mountain stream of southwest France. Journal of Fish Biology 71, 210-223.

Cucherousset J., Bouletreau S., Martino A., Roussel J.-M. \& Santoul F. (2012) Using stable isotope analyses to determine the ecological effects of non-native fishes. Fisheries Management and Ecology 19, 111-119.

Danchin E., Charmantier A., Champagne F.A., Mesoudi A., Pujol B. \& Blanchet S. (2011) Beyond DNA: integrating inclusive inheritance into an extended theory of evolution. Nature Review. Genetics 12, 475-486.

Darling J.A. \& Mahon A.R. (2011) From molecules to management: adopting DNA-based methods for 
monitoring biological invasions in aquatic environments. Environmental Research 111, 978-988.

Deagle B.E., Tollit D.J., Jarman S.N., Hindell M.A., Trites A.W. \& Gales N.J. (2005) Molecular scatology as a tool to study diet: analysis of prey DNA in scats from captive Steller sea lions. Molecular Ecology 14, 1831-1842.

DeYoung R.W. \& Honeycutt R.L. (2005) The molecular toolbox: genetic techniques in wildlife ecology and management. Journal of Wildlife Management 69, 1362-1384.

Dubut V., Sinama M., Martin J.F., Meglecz E., Fernandez J., Chappaz R. et al. (2010) Cross-species amplification of 41 microsatellites in European cyprinids: a tool for evolutionary, population genetics and hybridization studies. BMC Research Notes 3, 135.

Dudgeon D., Arthington A.H., Gessner M.O., Kawabata Z.I., Knowler D.J., Leveque C. et al. (2006) Freshwater biodiversity: importance, threats, status and conservation challenges. Biological Reviews 81, 163-182.

Ellegren H. \& Sheldon B.C. (2008) Genetic basis of fitness differences in natural populations. Nature 452, 169-175.

Estoup A. \& Guillemaud T. (2010) Reconstructing routes of invasion using genetic data: why, how and so what? Molecular Ecology 19, 4113-4130.

Facon B., Pointier J., Jarne P., Sarda V. \& David P. (2008) High genetic variance in life-history strategies within invasive populations by way of multiple introductions. Current Biology 18, 363-367.

Faulkner H. \& Copp G.H. (2001) A model for accurate drift estimation in streams. Freshwater Biology 46, 723-733.

Ficetola G.F., Miaud C., Pompanon F. \& Taberlet P. (2008) Species detection using environmental DNA from water samples. Biology Letters 4, 423-425.

Fiumera A.C., Parker P.G. \& Fuerst P.A. (2000) Effective population size and maintenance of genetic diversity in captive-bred populations of a Lake Victoria Cichlid. Conservation Biology 14, 886-892.

Forro L., Korovchinsky N.M., Kotov A.A. \& Petrusek A. (2008) Global diversity of cladocerans (Cladocera; Crustacea) in freshwater. Hydrobiologia 595, 177-184.

García-Berthou E. (2007) The characteristics of invasive fishes: what has been learned so far? Journal of Fish Biology 71, 33-55.

Geller J.B., Darling J.A. \& Carlton J.T. (2010) Genetic perspectives on marine biological invasions. Annual Review of Marine Science 2, 367-393.

Gozlan R.E. (2008) Introduction of non-native freshwater fish: is it all bad? Fish and Fisheries 9, 106-115.

Gozlan R.E., Britton J.R., Cowx I. \& Copp G.H. (2010) Current knowledge on non-native freshwater fish introductions. Journal of Fish Biology 76, 751-786.

Hänfling B. (2007) Understanding the establishment success of non-indigenous fishes: lessons from population genetics. Journal of Fish Biology 71, 115-135.
Hebert P.D.N., Cywinska A., Ball S.L. \& DeWaard J.R. (2003) Biological identifications through DNA barcodes. Proceedings of the Royal Society of London. Series B, Biological Sciences 270, 313-321.

Hickey V. (2010) The quagga mussel crisis at Lake Mead National Recreation Area, Nevada (USA). Conservation Biology 24, 931-937.

Hochberg M.E. \& Gotelli N.J. (2005) An invasions special issue. Trends in Ecology \& Evolution 20, 211.

Jerde C.L., Mahon A.R., Chadderton W.L. \& Lodge D.M. (2011) "Sight-unseen" detection of rare aquatic species using environment DNA. Conservation Letters 4, 150 157.

Jeschke J.M. \& Strayer D.L. (2006) Determinants of vertebrate invasion success in Europe and North America. Global Change Biology 12, 1608-1619.

Kawamura K., Yonekura R., Ozaki Y., Katano O., Taniguchi Y. \& Saitoh K. (2010) The role of propagule pressure in the invasion success of bluegill sunfish, Lepomis macrochirus, in Japan. Molecular Ecology 19, 53715388.

Kelly D.W., Muirhead J.R., Heath D.D. \& Macisaac H.J. (2006) Contrasting patterns in genetic diversity following multiple invasions of fresh and brackish waters. Molecular Ecology 15, 3641-3653.

Knaepkens G., Baekelandt K. \& Eens M. (2006) Fish pass effectiveness for bullhead (Cottus gobio), perch (Perca fluviatilis) and roach (Rutilus rutilus) in a regulated lowland river. Ecology of Freshwater Fish 15, 20-29.

Kolar C. \& Lodge D. (2001) Progress in invasion biology: predicting invaders. Trends in Ecology and Evolution 16, 199-204.

Kolbe J.J., Glor R.E., Schettino L.R.G., Lara A.C., Larson A. \& Losos J.B. (2004) Genetic variation increases during biological invasion by a Cuban lizard. Nature 431, 177181.

Koskinen M., Haugen T. \& Primmer C. (2002) Contemporary fisherian life-history evolution in small salmonid populations. Nature 419, 826-830.

Lawler J.J., Aukema J.E., Grant J.B., Halpern B.S., Kareiva P., Nelson C.R. et al. (2006) Conservation science: a 20year report card. Frontier in Ecology and the Environment 4, 473-480.

Lee C.E. (2002) Evolutionary genetics of invasive species. Trends in Ecology and Evolution 17, 386-391.

Lodge D. (1993) Biological invasions: lessons for ecology. Trends in Ecology and Evolution 8, 133-137.

Luikart G., Ryman N., Tallmon D.A., Schwartz M.K. \& Allendorf F.W. (2010) Estimation of census and effective population sizes: the increasing usefulness of DNA-based approaches. Conservation Genetics 11, 355-373.

Mack R.N., Simberloff D., Lonsdale W.M., Evans H., Clout M. \& Bazzaz F.A. (2000) Biotic invasions: causes, 
epidemiology, global consequences, and control. Ecological Applications 10, 689-710.

Markova S., Dufresne F., Rees D.J., Cerný M. \& Kotlik P. (2007) Cryptic intercontinental colonization in water fleas Daphnia pulicaria inferred from phylogenetic analysis of mitochondrial DNA variation. Molecular Phylogenetics and Evolution 44, 42-52.

Miura O. (2007) Molecular genetic approaches to elucidate the ecological and evolutionary issues associated with biological invasions. Ecological Research 22, 876-883.

Moyle P.B. \& Light T. (1996) Biological invasions of fresh water: empirical rules and assembly theory. Biological Conservation 78, 149-161.

Muirhead J.R., Gray D.K., Kelly D.W., Ellis S.M., Heath D.D. \& Macisaac H.J. (2008) Identifying the source of species invasions: sampling intensity vs. genetic diversity. Molecular Ecology 17, 1020-1035.

Neilson M.E. \& Stepien C.A. (2009) Evolution and phylogeography of the tubenose goby genus Proterorhinus (Gobiidae: Teleostei): evidence for new cryptic species. Biological Journal of the Linnean Society 96, 664-684.

Nielsen L.A. \& Johnson D.L. (1983) Fisheries Techniques. Bethesda, MD: American Fisheries Society, 468 pp.

Nolte A.W., Freyhof J., Stemshorn K.C. \& Tautz D. (2005) An invasive lineage of sculpins, Cottus sp. (Pisces, Teleostei) in the Rhine with new habitat adaptations has originated from hybridization between old phylogeographic groups. Proceedings of the Royal Society of London. Series B, Biological Sciences 272, 2379-2387.

Novak S.J. (2007) The role of evolution in the invasion process. Proceeding of the National Academy of Sciences USA 104, 3671-3672.

Osborne M.J., Davenport S.R., Hoagstrom C.W. \& Turner T.F. (2010) Genetic effective size, Ne, tracks density in a small freshwater cyprinid, Pecos bluntnose shiner ( $\mathrm{No}$ tropis simus pecosensis). Molecular Ecology 19, 28322844.

Piry S., Alapetite A., Cornuet J.M., Paetkau D., Beaudoin L. \& Estoup A. (2004) GENCLASS2: a software for genetic assignment and first-generation migrant detection. Journal of Heredity 95, 536-539.

Rahel F. (2007) Biogeographic barriers, connectivity and homogenization of freshwater faunas: it's a small world after all. Freshwater Biology 52, 696-710.

Renaut S., Nolte A.W., Rogers S.M., Derome N. \& Bernatchez L. (2011) SNP signatures of selection on standing genetic variation and their association with adaptive phenotypes along gradients of ecological speciation in lake whitefish species pairs (Coregonus spp.). Molecular Ecology 20, 545-559.

Ricciardi A. (2007) Are modern biological invasions an unprecedented form of global change? Conservation Biology 21, 329-336.
Roberge C., Blanchet S., Dodson J.J., Guderley H. \& Bernatchez L. (2008) Disturbance of social hierarchy by an invasive species: a gene transcription study. PLOS ONE 36, 2408.

Roman J. \& Darling J. (2007) Paradox lost: genetic diversity and the success of aquatic invasions. Trends in Ecology \& Evolution 22, 454-464.

Sax D.F., Stachowicz J.J., Brown J.H., Bruno J.F., Dawson M.N., Gaines S.D. et al. (2007) Ecological and evolutionary insights from species invasions. Trends in Ecology \& Evolution 22, 465-471.

Selkoe K.A. \& Toonen R.J. (2006) Microsatellites for ecologists: a practical guide to using and evaluating microsatellite markers. Ecology Letters 9, 615-629.

Simberloff D. (2003) How much information on population biology is needed to manage introduced species? Conservation Biology 17, 83-92.

Simberloff D. (2005) The politics of assessing risk for biological invasions: the USA as a case study. Trends in Ecology \& Evolution 20, 216-222.

Simon K.S. \& Townsend C.R. (2003) Impacts of freshwater invaders at different levels of ecological organisation, with emphasis on salmonids and ecosystem consequences. Freshwater Biology 48, 982-994.

Simon A., Britton J.R., Gozlan R.E., van Oosterhout C., Volckaert F.A.P. \& Hänfling B. (2011) The invasion of topmouth gudgeon in Europe originates from a single introduction of an admixed source population followed by long-distance dispersal. PLoS ONE 6, e18560.

Stepien C.A. \& Tumeo M.A. (2006) Invasion genetics of Ponto-Caspian gobies in the Great Lakes: a 'cryptic' species, absence of founder effects, and comparative risk analysis. Biological Invasions 8, 61-78.

Storz J. \& Beaumont M. (2002) Testing for genetic evidence of population expansion and contraction: an empirical analysis of microsatellite DNA variation using a hierarchical Bayesian model. Evolution 56, 154-166.

Strauss S.Y., Lau J.A. \& Carroll S.P. (2006) Evolutionary responses of natives to introduced species: what do introductions tell us about natural communities? Ecology Letters 9, 357-374.

Suarez A.V. \& Tsutsui N.D. (2008) The evolutionary consequences of biological invasions. Molecular Ecology 17, $351-360$.

Thibault I., Bernatchez L. \& Dodson J.J. (2009) The contribution of newly established populations to the dynamics of range expansion in a one-dimensional fluvial-estuarine system: rainbow trout (Oncorhynchus mykiss) in Eastern Quebec. Diversity and Distributions 15, 1060-1072.

Valiente A., Juanes F., Nuarez P. \& García-Vazquez E. (2010) Brown trout (Salmo trutta) invasiveness: plasticity in life-history is more important than genetic variability. Biological Invasions 12, 451-462. 
Vander Zanden M., Casselman J. \& Rasmussen J. (1999) Stable isotope evidence for the food web consequences of species invasions in lakes. Nature 401, 464-467.

Vidal O., García-Berthou E., Tedesco P.A. \& García-Marin J.L. (2010) Origin and genetic diversity of mosquitofish (Gambusia holbrooki) introduced to Europe. Biological Invasions 12, 841-851.
Volpe J., Anholt B. \& Glickman B. (2001) Competition among juvenile Atlantic salmon (Salmo salar) and steelhead (Oncorhynchus mykiss): relevance to invasion in British Columbia. Canadian Journal of Fisheries and Aquatic Sciences 58, 197-207.

Whitlock M.C. (2008) Evolutionary inference from QST. Molecular Ecology 17, 1885-1896. 